\title{
Presence of the snow leopard Panthera uncia confirmed at four sites in the Chinese Tianshan Mountains
}

\author{
Paul J. Buzzard, Roller MaMing, Mardan Turghan \\ JiAWU XIONG and TONG ZHANG
}

\begin{abstract}
The Endangered snow leopard Panthera uncia is a flagship species of mountainous central Asia, and a conservation concern. China has the largest extent of potential snow leopard habitat and is thus crucial for snow leopard conservation. There are many challenges to snow leopard conservation in China, however, and there is still little information on the species for many geographical locations, including the Tianshan Mountains of Xinjiang province, which are important because they potentially connect snow leopard populations in Krygyzstan and Kazakhstan with those in Mongolia. We used camera traps in four areas across eastern, central and western Tianshan, with a total survey effort of 3,216 camera-trapping days. We confirmed the presence of snow leopards and an abundance of potential snow leopard prey, including the Siberian ibex Capra sibirica, in all areas. We found $2-3$ individual adult snow leopards at each site, with relatively limited survey effort, and more study is needed to fully investigate the importance of the Tianshan Mountains for the species. Establishing more protected areas is essential for snow leopard conservation, and we have used data from this study to apply for protected area status for several areas.
\end{abstract}

Keywords Camera trapping, China, Panthera uncia, protected area, Siberian ibex, snow leopards, Tianshan Mountains

The snow leopard Panthera uncia, a flagship species 1 of mountainous central Asia, is categorized as Endangered on the IUCN Red List (Jackson et al., 2008). China has the largest number of snow leopards and the largest area of potential habitat of the 12 range countries (McCarthy \& Mallon, 2016). China is thus crucial to snow leopard conservation, but there are many challenges to the conservation of the species, including poaching, mining,

Paul J. Buzzard (Corresponding author) Detroit Zoological Society, 8450 W. 10 Mile Road, Royal Oak, MI 48067, USA. E-mail pbuzzard@dzs.org

Roller MaMing and Mardan Turghan Xinjiang Institute of Ecology and Geography, Chinese Academy of Sciences, Urumqi, China

Jiawu Xiong and Tong Zhang Central South Forest Inventory and Planning Institute, Changsha 410014, China

Received 15 May 2017. Accepted 22 May 2017. First published online 13 July 2017. and infrastructure development. More research is needed for effective conservation of the species (Alexander et al., 2016; Li et al., 2016). To address this we provide data from camera traps at four areas across the Tianshan Mountains, including some areas not previously systematically surveyed. The Tianshan Mountains stretch across Xinjiang province in north-west China and provide a potential link between snow leopard populations in Kazakhstan/Kyrgyzstan and Mongolia. These populations have been recognized as the subspecies $P$. uncia uncia and $P$. uncia irbis, respectively (Janecka et al., 2017). Given their geographical location, the Tianshan Mountains are potentially important to snow leopard conservation, and it is a priority to determine the snow leopard's status there (Snow Leopard Network, 2014).

In China, snow leopard conservation efforts increased in the late 1980 os when the snow leopard was protected as a class 1 species and several nature reserves were established (e.g. Tomur Feng $\left(250 \mathrm{~km}^{2}\right)$; Li et al., 2016). Despite these positive steps, early work by Schaller et al. (1988) in the Tianshan Mountains and other parts of Xinjiang found relatively few signs of snow leopards. In Tomur Feng reserve in the western Tianshan, adjacent to the Krygyzstan border, there was more evidence of snow leopard presence than in the Harendanban Shan of the central Tianshan (Schaller et al., 1988). Subsequent work at Tomur Feng confirmed its importance for snow leopards (e.g. Ma et al., 2006; MaMing et al., 2013), and more recent work confirmed snow leopard presence west of Jinghe in the western Tianshan, near Kazakhstan (Pan et al., 2016). Wu et al. (2015) reported a relatively high density of Siberian ibex Capra sibirica $\left(154 \pm\right.$ SD 23 ibex per $\left.100 \mathrm{~km}^{2}\right)$ in the Tianshan south of Urumqi and estimated 1.3-2.6 snow leopards per $100 \mathrm{~km}^{2}$ could be supported.

To detect the presence of snow leopards and potential prey, including Siberian ibex, red deer Cervus elaphus and wild boar Sus scrofa, in Tianshan we set heat/motionsensing infrared camera traps that recorded both photographs and videos (Bushnell/Reconyx). To maximize the area covered and the number of snow leopards captured we set cameras singly near snow leopard sign or in areas likely to be used by snow leopards, such as along valleys. We set cameras at 1,995-5,000 $\mathrm{m}$ altitude and at least $500 \mathrm{~m}$ apart or in different valleys. We set 44 cameras during December 2014-June 2015 and/or January-May 2016 at four 
TABLE 1 Numbers of camera sites, camera-days, and independent images or events recorded (adult snow leopard Panthera uncia individuals identified), and camera-trapping rates (events per 100 camera-days), for the four study areas in the Tianshan Mountains of Xinjiang, China (Fig. 1).

\begin{tabular}{lccll}
\hline $\begin{array}{l}\text { Study location } \\
\text { (area) }\end{array}$ & $\begin{array}{l}\text { No. of } \\
\text { camera sites }\end{array}$ & $\begin{array}{l}\text { No. of } \\
\text { camera-days }\end{array}$ & $\begin{array}{l}\text { No. of events } \\
\text { (no. of individuals) }\end{array}$ & $\begin{array}{l}\text { No. of events } \\
\text { per } 100 \text { camera-days }\end{array}$ \\
\hline Urumqi $\left(45 \mathrm{~km}^{2}\right)$ & 5 & 475 & $22(3)$ & 4.6 \\
Wusu $\left(220 \mathrm{~km}^{2}\right)$ & 15 & 1,649 & $11(2)$ & 0.7 \\
Jinghe $\left(75 \mathrm{~km}^{2}\right)$ & 8 & 520 & $24(2)$ & 4.6 \\
Ili $\left(200 \mathrm{~km}^{2}\right)$ & 15 & 572 & $15(3)$ & 2.6 \\
\hline
\end{tabular}

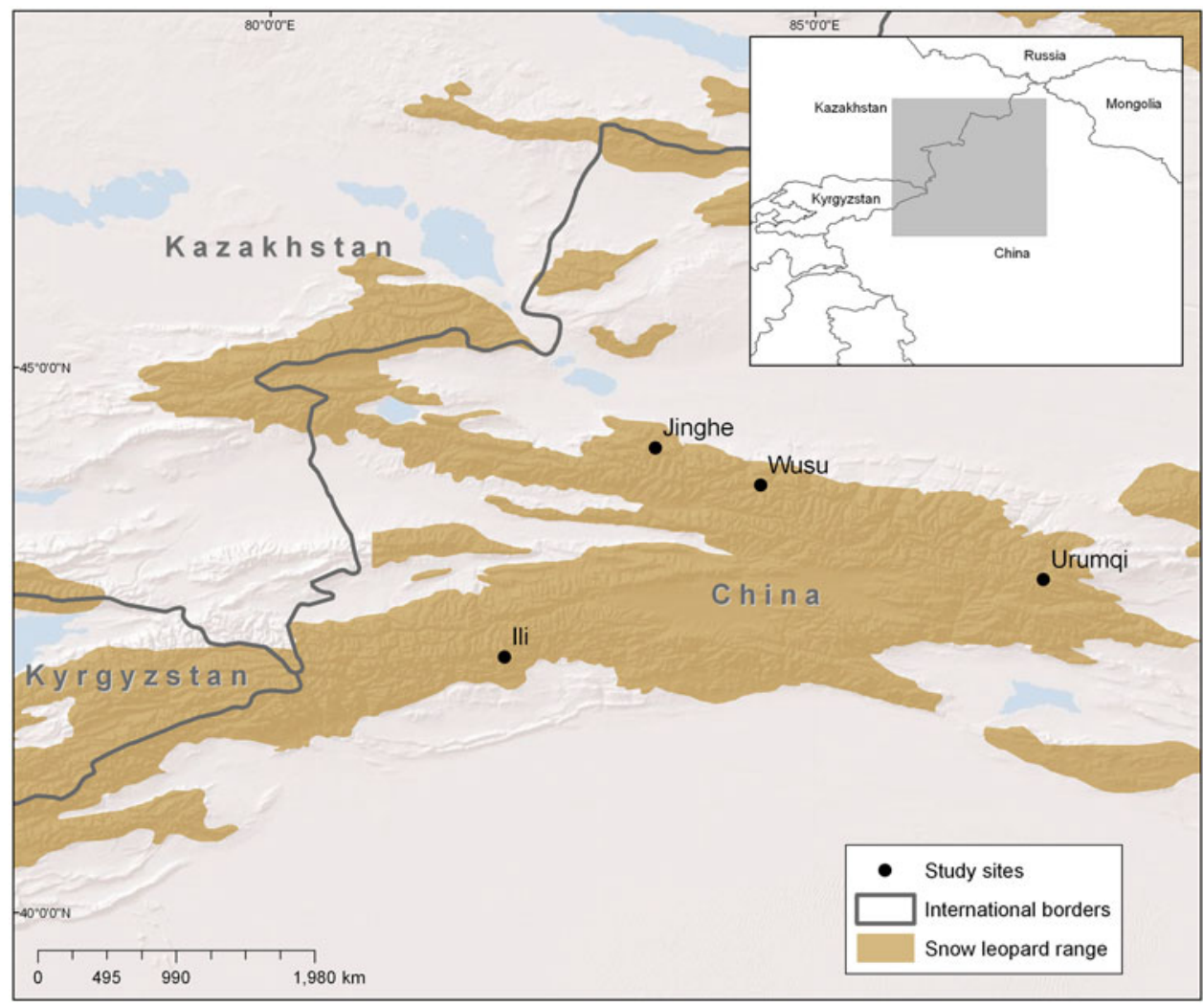

FIg. 1 The snow leopard Panthera uncia range (Jackson et al., 2008), and the four study areas in the Tianshan Mountains of Xinjiang, China. study areas c. 65-200 km apart: (1) south of Urumqi, (2) four valleys $20-30 \mathrm{~km}$ apart (Maolugou, Bayinggou, Toudagou and Dianzhangou) near Wusu, (3) east of Jinghe, and (4) around the Buzarde valley near Ili and the Kazakhstan border (Table 1; Fig. 1).

Consecutive photographs of snow leopards and other species at the same site were deemed independent events when there was at least a 1-hour interval between them (Rovero \& Marshall, 2009). To determine survey effort we calculated the number of camera trap-days from the date of each camera's deployment until the date of its retrieval or until the last photograph was taken. To compare with other snow leopard studies we calculated camera trapping rates (events per 100 camera-days), and to demonstrate the relative importance of areas we distinguished among snow leopard individuals in the photographs and videos by comparing spot patterns and scars and other distinguishing marks. Although the cameras were set singly, the combination of pictures and videos often provided clear views of both sides of individuals, and the identification of individuals was confirmed by several observers.

At each site potential prey of the snow leopard, particularly Siberian ibex, were common; for example, ibex herds of 20-6o individuals were observed frequently while setting up cameras near Wusu, and at each study area we captured multiple events of ibex in groups of at least 3-20 individuals (from a low of six events at Jinghe to 86 events at Wusu). We also captured 11 events of wild boar at Ili and three at Wusu, as well as one event of red deer at Urumqi and six at Wusu. Urumqi and Jinghe had the highest camera-trapping rates for snow leopards, and Wusu had the lowest (Table 1); snow leopards were recorded in only two of the valleys 
TABLE 2 Details of the protected areas for which formal applications were made to the Chinese government based on snow leopard data from the Tianshan Mountains (Fig. 1).

\begin{tabular}{lllr}
\hline $\begin{array}{l}\text { Protected } \\
\text { area }\end{array}$ & Class & Location & \multicolumn{1}{l}{$\begin{array}{l}\text { Area } \\
\text { (ha) }\end{array}$} \\
\hline Wulan Nur & Provincial & $84^{\circ}-84^{\circ} 30^{\prime} \mathrm{E} ; 43^{\circ} 45^{\prime}-44^{\circ} \mathrm{N}$ & 45,000 \\
Zhaobishan & National & $87^{\circ} 17^{\prime}-87^{\circ} 24^{\prime} \mathrm{E} ; 43^{\circ} 10^{\prime}-43^{\circ} 24^{\prime} \mathrm{N}$ & 750 \\
Toutunhe & National & $86^{\circ} 45^{\prime}-87^{\circ} \mathrm{E} ; 43^{\circ} 16^{\prime}-43^{\circ} 31^{\prime} \mathrm{N}$ & 1,410 \\
\hline
\end{tabular}

surveyed in Wusu (Maolugou and Bayinggou). We identified at least two or three individual adult snow leopards at each site (Table 1). At Maolugou valley, Wusu, two adult snow leopards were photographed together, and in Urumqi two adults were recorded within a 1-minute interval.

Given their geographical location between Central Asia and Mongolia (Snow Leopard Network, 2014), the Tianshan Mountains are a conservation priority for snow leopards and our study demonstrates the importance of the Tianshan Mountains for snow leopard conservation. We confirmed the presence of several adult snow leopards and large numbers of potential prey, such as Siberian ibex, at multiple areas across the east, central and western Tianshan. In addition, our study supports previous findings in the western Tianshan, where Pan et al. (2016) recorded 1115 individual adult snow leopards in $192 \mathrm{~km}^{2}$. Given this potential for large numbers of snow leopards, more work is necessary at our study sites and across the Tianshan to clarify snow leopard density and status. For example, we recorded three individuals ( 2 males and 1 female) south of Urumqi with relatively limited trapping effort. These same individuals were also recorded in a much greater survey effort adjacent to our study area by Xinjiang Wild Watchers, who obtained photographic evidence of at least 22 individual snow leopards, including 12 adults, in c. $100 \mathrm{~km}^{2}$ (Xing, 2016).

To enhance snow leopard conservation in Xinjiang there is an urgent need for more protected areas (Xu et al., 2014), and the Tianshan Mountains were the focus of a conservation and management plan workshop organized by the Xinjiang Forestry Bureau (Tianshan Snow Leopard Conservation Conference, 24-26 August 2016). Our data confirm the importance of several areas for snow leopards, and we have used these data as the basis for formal applications to the Chinese and Xinjiang Governments for multiple protected areas (Table 2).

\section{Acknowledgements}

We thank the State Forestry Administration of Xinjiang for assistance with this project; $\mathrm{Xu}$ Guohua and Wu Daoning for help with fieldwork; and Kim Williams-Guillén for help with the figure. Funding was received from Detroit Zoological Society and a 2015 conservation grant from the Snow Leopard Network. This research was conducted with the necessary approvals and permits from the appropriate institutions in China.

\section{Author contributions}

$\mathrm{PJB}, \mathrm{RM}$, and MT contributed to the study design, fieldwork, and writing the article. JX and TZ contributed to the study design and protected area applications.

\section{References}

Alexander, J.S., Zhang, C., Shi, K. \& Riordan, P. (2016) A spotlight on snow leopard conservation in China. Integrative Zoology, 11, 308-321.

Jackson, R., Mallon, D., McCarthy, T., Chundawat, R.A. \& Haвib, B. (2008) Panthera uncia. In The IUCN Red List of Threatened Species 2008: e.T22732A9381126. Http://dx.doi.org/10. 2305/IUCN.UK.2008.RLTS.T22732A9381126.en [accessed 25 May 2017].

Janecka, J.E., Zhang, Y., Li, D., Munkhtsog, B., BayaraA, M., GalsandorJ, N. et al. (2017) Range-wide snow leopard phylogeography supports three subspecies. Journal of Heredity, http://academic.oup.com/jhered/article-lookup/doi/10.1093/jhered/ esxo44.

Li, J., Xiao, L. \& Lu, Z. (2016) Challenges of snow leopard conservation in China. Science China Life Sciences, 59, 637-639.

Ma, M., Xu, F., Chundawat, R.S., Jumabay, K., Wu, Y., Aizezi \& $\mathrm{ZHU}_{\mathrm{HU}}$ M. (2006) Camera trapping of snow leopards for the photo capture rate and population size in the Muzat Valley of Tianshan Mountains. Acta Zoologica Sinica, 52, 788-793. [In Chinese]

MaMing, R., Xu, F. \& Cheng, Y. (2013) Snow Leopards in Xinjiang. Science Press, Beijing, China.

McCarthy, T. \& Mallon, D. (eds) (2016) Snow Leopards. Academic Press, London, UK.

Pan, G., Alexander, J.S., Riordan, P., Shi, K., Kederhan \& Yang, H. (2016) Detection of a snow leopard population in northern Bortala, Xinjiang, China. CATnews, 63, 29-30.

Rovero, F. \& MArshall, A.R. (2009) Camera trapping photographic rate as an index of density in forest ungulates. Journal of Applied Ecology, 46, 1011-1017.

Schaller, G.B., Hong, L., Talipu, Junrang, R. \& Mingjiang, Q. (1988) The snow leopard in Xinjiang, China. Oryx, 22, 197-204.

SNOW LeOpARd Network (2014) Snow Leopard Survival Strategy. Revised 2014 Version. Snow Leopard Network, Seattle, USA.

Wu, D., MaMing, R., Xu, G., Zhu, X. \& Buzzard, P. (2015) Relationship between ibex and snow leopard population density in Tian Shan. Selevinia, 23, 186-190.

XING, R. (2016) Snow Leopard Survey and Conservation Project in Xinjiang. Tianshan Snow Leopard Forum, 24-26 August 2016.

Xu, G., Maming, R., Buzzard, P.J. \& Blank, D. (2014) Nature Reserves in Xinjiang: a snow leopard paradise or refuge for how long? Selevinia, 22, 144-149.

\section{Biographical sketches}

PAUL BUZZARD's work focuses on protected area management and wildlife monitoring with remote sensing technology. ROLLER MaMing, Mardan Turghan, Jiawu Xiong, and Tong $Z_{H A N G}$ all focus on snow leopard, ungulate and bird research as well as protected area management. 